\title{
Metabolic features in chronic HCV infected patients
}

\author{
Mihaela Andreea Rădulescu ${ }^{1,2^{*}}$, Victoria Aramă ${ }^{1,2}$, Daniela loana Munteanu', Cristina Popescu ${ }^{1,2}$, \\ Raluca Mihaela Năstase ${ }^{1}$, Violeta Molagic ${ }^{1}$, Anca-Ruxandra Negru' ${ }^{1}$, Irina Lăpădat', Viorica Poghirc ${ }^{1}$, \\ Sorin Ștefan Aramă ${ }^{1,3}$, Adrian Streinu-Cercel ${ }^{1,2}$
}

From The 9th Edition of the Scientific Days of the National Institute for Infectious Diseases Prof Dr Matei Bals Bucharest, Romania. 23-25 October 2013

\section{Background}

In recent years a large amount of literature data emphasizes the interrelationship between pathogenic mechanisms of chronic hepatitis $\mathrm{C}$ virus (HCV) infection and lipid and glucid metabolism. In this study we aimed to characterize lipid and glucidic metabolic patterns in chronically $\mathrm{HCV}$-infected patients and to evaluate the role of $\mathrm{HCV}$ on cardiovascular risk (CVR).

\section{Methods}

We conducted a cross-sectional analysis on chronic HCVinfected adult patients, monitored at the National Institute of Infectious Diseases "Prof. Dr. Matei Balş". Patients with diabetes mellitus, chronic alcohol consumption, other chronic liver diseases, HBV or HIV co-infections were excluded. We recorded demographic data, $\mathrm{HCV}$ infection history, personal and family history of CVR factors. We measured height and weight for body mass index, waist to hip ratio, blood pressure and we assessed the 10 years CVR using Framingham score. Blood samples were tested for lipid profile, serum glucose, glycosylated hemoglobin $\left(\mathrm{HbA}_{1 \mathrm{c}}\right)$, liver enzymes, and viral load (VL). Liver histology was assessed by Fibromax (Biopredictive).

\section{Results}

Seventy-six patients with a median age of 51years (IQR 44.25-58.0) were included. Sex ratio was F:M=1.53. Median VL was $118500 \mathrm{IU} / \mathrm{mL}$ (IQR 0-600951). Twenty-five percent (19/76) of the patients had no fibrosis (F0), 51.3\% (39/76) had hepatitis (F1-2), 6.5\% (5/76) had a fibrosis score equivalent to transition to cirrhosis (F3), and 17.1\%

\footnotetext{
* Correspondence: michelle_radulescu@yahoo.com

'National Institute for Infectious Diseases "Prof. Dr. Matei Balş", Bucharest, Romania

Full list of author information is available at the end of the article
}

(13/76) had cirrhosis (F4). Mean serum cholesterol, LDL and triglycerides were $187 \mathrm{mg} / \mathrm{dL}$ (IQR 166-220), $119 \mathrm{mg} /$ $\mathrm{dL}$ (IQR 93-147) and respectively $94 \mathrm{mg} / \mathrm{dL}$ (IQR 69.25132.0). Patients with no fibrosis were more frequently younger and females $(\mathrm{p}=0.000$, respectively 0.015$)$, had higher cholesterol $(\mathrm{p}=0.014)$ and LDL levels $(\mathrm{p}=0.009)$ and lower VL $(p=0.017)$ and CVR according to Framingham score $(p=0.000)$. Patients with cirrhosis were more frequently males $(\mathrm{p}=0.033)$, and had higher viral load $(\mathrm{p}=0.011)$ and serum glucose $(\mathrm{p}=0.027)$. Fibrosis score correlated to age $(\mathrm{p}=0.000)$, VL $(\mathrm{p}=0.001)$, higher $\mathrm{CVR}$ $(\mathrm{p}=0.001)$, low LDL $(\mathrm{p}=0.034)$, high glucose $(\mathrm{p}=0.031)$. The VL correlated to HDL $(\mathrm{p}=0.023)$ and with lower $\mathrm{HbA}_{1 \mathrm{c}}$ levels $(\mathrm{p}=0.022)$.

\section{Conclusions}

In patients with chronic $\mathrm{HCV}$ infection although high fibrosis correlates to better lipid profiles, it also correlates to higher cardiovascular risk.

\section{Acknowledgment \\ POSDRU Project no 107/1.5/S/82839}

\section{Authors' details}

"National Institute for Infectious Diseases "Prof. Dr. Matei Bals", Bucharest, Romania. ${ }^{2}$ Carol Davila University of Medicine and Pharmacy, Bucharest, Romania. ${ }^{3}$ Dr. Ioan Cantacuzino Clinical Hospital, Bucharest, Romania.

Published: 16 December 2013

doi:10.1186/1471-2334-13-S1-031

Cite this article as: Rădulescu et al:: Metabolic features in chronic HCV infected patients. BMC Infectious Diseases 2013 13(Suppl 1):031.

\section{() Biomed Central}

C 2013 Rădulescu et al; licensee BioMed Central Ltd. This is an Open Access article distributed under the terms of the Creative Commons Attribution License (http://creativecommons.org/licenses/by/2.0), which permits unrestricted use, distribution, and reproduction in any medium, provided the original work is properly cited. 